\title{
Correspondence
}

\section{On the values of outpatients}

To the Editor:

The study by Fung and Cohen ${ }^{1}$ presents important aspects of the relationship between the anesthesiologist and his patient during the temporal phases of surgery. Nevertheless, we believe that this study contains some methodological flaws.

Firstly, important questions remained unanswered: were the initial interviews conducted by an anesthesiologist? How were the patients and anesthesiologists selected? What was the justification for the number of patients $(n=45)$ and anesthesiologists $(n=15)$ ? Secondly, the content of the questionnaire would be improved by screening several items not related to anesthesia care (e.g., the room(s) I awaken in is (are) comfortable), and items comprising more than one question (e.g., the anesthesiologist identifies all my concerns, encourages me to communicate those concerns, and then answers all my questions). Also, there are not enough respondents for the total number of items presented and the ranking of items is a pre-test procedure usually employed to remove questionable items.

Furthermore, the sample of patients included $84 \%$ $(27 / 32)$ of women. Care should have been taken, especially with a small sample, to balance the number of men and women. It is well known in the literature $^{2-3}$ that women do not prioritize the same aspects as men in the appreciation of their health care.

Finally, the development of this questionnaire is promising but in its present and precocious form it would strongly benefit from a thorough revision followed by a pilot study with a larger sample before it can be considered valid to determine the values of outpatients regarding anesthesia care.

Sylvie Le May MSc

Gilles Dupuis PhD

Marie-Christine Taillefer BSc

Montréal, Québec

\section{References}

1 Fung D, Cohen $M$. What do outpatients value most in their anesthesia care? Can J Anesth 2001; 48: 12-19.

2 Nathanson CA. Illness and the feminine role: a theoretical review. Soc Sci Med 1975; 9: 57-62.

3 Kring AM, Gordon AH. Sex differences in emotion: expression, experience, and physiology. J Pers Soc Psychol 1998; 74: 686-703.

\section{REPLY:}

We thank Le May and colleagues for their interest and comments.

As we acknowledged in our discussion, our study was too small to provide definitive answers or conclusions. We agree that its findings are preliminary but for two reasons we feel the study remains of value to anesthesiologists.

First, published studies using formal qualitative techniques are uncommon in anesthesia. These techniques have been undervalued in anesthesia research but, as demonstrated by this study, they offer a unique and efficient means to discover what our patients want. Insights acquired from formal interviewing and consensus methods, even if preliminary, are valuable in their own right.

Secondly, well-conducted qualitative investigations prior to questionnaire construction is neglected all too often in anesthesia ${ }^{1}$ but are essential to the content validity of questionnaires that seek ultimately to make reliable and valid measurements of satisfaction or quality of care. ${ }^{2}$ Testing of the questionnaire in one or more pilot trials is then required to produce a final mature version of the questionnaire. ${ }^{3-5}$

Our study (and our questionnaire) should be seen as a beginning not an end. Both as qualitative research or as a new questionnaire, the preliminary findings of our study await confirmation in future investigations.

Donald Fung MD

North Bay, Ontario

\section{References}

l Fung D, Cohen M. Measuring patient satisfaction with anesthesia care: a review of current methodology. Anesth Analg 1998; 87: 1089-98.

2 Nunally JC. Psychometric Theory, 2nd ed. New York: McGraw-Hill, 1978.

3 Meterko M, Rubin H, Ware JE, Hays RD, Berwick DM. Patient judgements of hospital quality questionnaire. Med Care 1990; 9(Suppl): S1-S44.

4 Dexter F, Aker J, Wright WA. Development of a measure of patient satisfaction with monitored anesthesia care: the Iowa satisfaction with anesthesia scale. Anesthesiology 1997; 87: 865-73. 
5 Myles PS, Hunt JO, Nightingale CE, et al. Development and psychometric testing of a quality of recovery score after general anesthesia and surgery in adults. Anesth Analg 1999; 88: 83-90.

\section{Anesthesia in the prone lithotomy position}

\section{To the Editor:}

We present our experience of the anesthetic management of patients in the rarely used prone lithotomy position (Figure).

During surgery, the prone position, if correctly applied, ensures free abdominal movement, is not associated with adverse effects on respiratory mechanics and improves lung volume and oxygenation. ${ }^{1,2}$ The lithotomy position, when superimposed on the prone position, improves cardiac output and hemodynamics, compensating for the decreased cardiac output due to impaired venous return in the prone position. ${ }^{3}$ Repair of a vesico-vaginal fistula under balanced anesthesia was performed in the prone lithotomy position in three ASA physical status I and II patients. In all cases, non-invasive blood pressure, central venous presure (CVP), ECG, airway pressure, end tidal carbon dioxide and oxygen saturation were monitored and changes in hemodynamic and respiratory variables were recorded. After the change of position to prone lithotomy, all variables remained stable except for a rise in airway pressure in the range of +1 to $+2 \mathrm{~cm} \mathrm{H}_{2} \mathrm{O}$ in one patient but without change in end tidal carbon dioxide tension and oxygen saturation. Another patient had a moderate rise of $\mathrm{CVP}\left(+2\right.$ to $\left.+5 \mathrm{~cm} \mathrm{H}_{2} \mathrm{O}\right)$. Peripheral nerve injury did not occur in any of the patients. The variables returned to baseline levels after patients were placed in the supine position after surgery, before extubation.

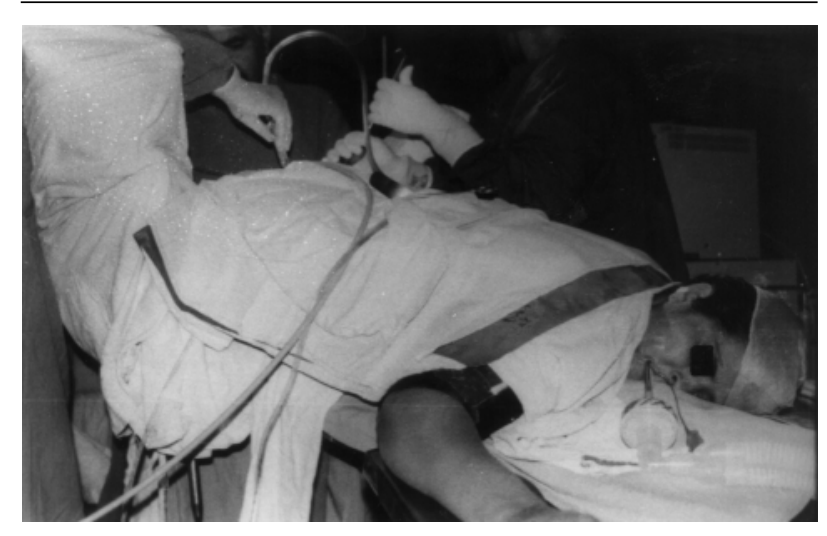

FIGURE Surgical repair of vesico-vaginal fistula in the prone lithotomy position.
On the basis of the experience gained during these three cases, we suggest that surgery in the prone lithotomy position is not associated with major cardiovascular or respiratory derangements intraoperatively.

Shashi Srivastava MD

Chandra Kant Pandey MD

Lucknow, India

\section{References}

1 Pelosi P, Croci M, Calappi E, et al. The prone positioning during general anesthesia minimally affects respiratory mechanics while improving functional residual capacity and increasing oxygen tension. Anesth Analg 1995; 80: 955-60.

2 Pelosi P, Croci M, Calappi E, et al. Prone positioning improves pulmonary function in obese patients during general anesthesia. Anesth Analg 1996; 83: 578-83.

3 Cucchiara RF, Ronal JF. Patient positioning. In: Miller RD (Ed). Anesthesia, 5 ed. New York: Churchill Livingstone Inc., 1999: 1017-32.

4 Thompson JD. Vesicovaginal and urethrovaginal fistula. In: Rock JA, Thompson JD (Ed). Te Linde's Operative Gynecology, $8^{\text {th }}$ ed. Philadelphia: Lippincott-Raven,

1997: 1175-1205.

\section{Cost and resource implications of under- graduate simulator-based education}

To the Editor:

Medical education has been recognized as a costly undertaking especially when innovations are introduced. Rothman and Cohen point out that standardized assessments like the Objective Structured Clinical Examinations (OSCE) are logistically complex and expensive. ${ }^{1}$ Interest in the use of anesthesia simulators for both educational and assessment purposes has increased as more medical schools acquire this technology. However, issues related to the financial and faculty resources cannot be ignored.

TABLE Estimation of operational costs

\begin{tabular}{lll}
\hline Item & Annual cost & $\begin{array}{l}\text { Cost per } \\
\text { student } \\
(C d n \$)\end{array}$ \\
\hline Simulator equipment and supplies & $3,500.00$ & 19.77 \\
Computer operator & $4,500.00$ & 25.42 \\
$\mathrm{CO}_{2}$ cylinders & 300.00 & 1.69 \\
Videotapes & 180.00 & 1.02 \\
Office equipment and supplies & 324.00 & 1.83 \\
Total & $8,804.00$ & 49.73 \\
\hline
\end{tabular}

